\title{
Knowledge in the Making: What Engineering Students are Learning in Mak- erspaces
}

\section{Dr. Louis S. Nadelson, University of Central Arkansas}

Louis S. Nadelson has a BS from Colorado State University, a BA from the Evergreen State College, a MEd from Western Washington University, and a PhD in educational psychology from UNLV. His scholarly interests include all areas of STEM teaching and learning, inservice and preservice teacher professional development, program evaluation, multidisciplinary research, and conceptual change. Nadelson uses his over 20 years of high school and college math, science, computer science, and engineering teaching to frame his research on STEM teaching and learning. Nadelson brings a unique perspective of research, bridging experience with practice and theory to explore a range of interests in STEM teaching and learning.

\section{Dr. Idalis Villanueva, Utah State University}

Dr. Villanueva is an Assistant Professor in the Engineering Education Department and an Adjunct Professor in the Bioengineering Department in Utah State University. Her multiple roles as an engineer, engineering educator, engineering educational researcher, and professional development mentor for underrepresented populations has aided her in the design and integration of educational and physiological technologies to research 'best practices' for student professional development and training. In addition, she is developing methodologies around hidden curriculum, academic emotions and physiology, and engineering makerspaces.

\section{Dr. Jana Bouwma-Gearhart, Oregon State University}

Jana L. Bouwma-Gearhart is an associate professor of STEM education at Oregon State University. Her research widely concerns improving education at research universities. Her earlier research explored enhancements to faculty motivation to improve undergraduate education. Her more recent research concerns organizational change towards postsecondary STEM education improvement at research universities, including the interactions of levers (people, organizations, policy, initiatives) of change and documenting the good, hard work required across disciplinary boundaries to achieve meaningful change in STEM education.

\section{Sarah Lanci, Colorado Mesa University}

Sarah Lanci is an Assistant Professor of Mechanical Engineering at Colorado Mesa University. She received her B.S. degree in Materials Science and Engineering at Michigan State University and her M.S. degree in Metallurgical Engineering at Colorado School of Mines. Following graduate school, Sarah worked as a part and process engineer at an investment casting facility, PCC Structurals, in Portland, OR for seven years before transitioning to her current position at CMU where she teaches introductory design, materials science, and manufacturing-focused courses. Sarah's research interests include aspects of project-based learning and enhancing 21 st century skills in undergraduate engineering students.

\section{Kate Youmans, Utah State University}

Kate Youmans is a PhD student in the Department of Engineering Education at Utah State University. Kate earned her bachelor's degree in Mechanical Engineering from Worcester Polytechnic Institute and worked in the medical device industry designing surgical instruments before focusing on engineering outreach in MIT's Office of Engineering Outreach Programs. After receiving her master's degree in Science Education from Boston University, Kate helped open the American International School of Utah, a K-12 charter school in Salt Lake City. In her role as STEM Director Kate developed the schools programs in Computer Science, Robotics and Design Thinking.

\section{Cindy Ann Lenhart, Oregon State University}


Cindy Lenhart is a graduate research assistant working on her Ph.D in Education at Oregon State University. During her first year, she was selected as a Provost's Distinguished Graduate Fellow by the Graduate School of Education. Cindy previously served as the Vice President for Community College Relations for Achieving the Dream, Inc., managing the Working Students Success Network, Engaging Adjunct Faculty, and other funded initiatives as well as leading Achieving the Dream's teaching and learning programs and network-engagement activities. Prior to joining Achieving the Dream, Cindy served for more than 20 years in community colleges as an associate vice president for instruction, a department chair, and a faculty member. Cindy began her career as a middle school and high school teacher.

\section{Mrs. Alexis K. Van Winkle, University of Central Arkansas}




\section{Knowledge in the Making: What Engineering Students are Learning in Makerspaces}

\section{Introduction}

Extensive funding and resources have been allocated to support the integration of makerspaces in undergraduate engineering programs and, with greater investment, there is growing likelihood that engineering students are expected to use the spaces as part of their coursework. The investment in and placement of the spaces within colleges of engineering, specifically, provide warrant for anticipating that engineering faculty members are assigning projects that require students to engage in the space to complete the assignments.

Makerspaces are usually well equipped with rapid prototyping equipment, hand tools, computers, and other equipment that could be used to make or create products or prototypes. Makerspaces have gained popularity [1] and continue to be popular with the expectation that students interacting in the spaces will learn a range of skills and content [2]-[5]. Promotion of makerspaces is based on the expectation that when students access and engage in making activities, they are also engaging in some of the practices and norms of engineers. The spaces provide a unique context for research and the exploration of what students may be learning in professionally-geared learning environments. For example, some of the research on learning in makerspaces has focused on student achievement of engineering program goals for learning outcomes when they use of the spaces as part of their engineering preparation programs [6]-[8]. Other university-based makerspace research projects have focused more on students' preferences for the spaces [9] or other space-related constructs such as creativity [10].

Yet little is still known regarding... Our research concerns the perceptions, experiences, and learning by the engineering students and faculty members working within university-based spaces associated with formal engineering programming. For this case study research, we conducted a combination of observations and interviews of students and faculty members working in engineering program-embedded makerspaces. This paper focuses on one of our six university cases - a makerspace embedded into an engineering education program at a large research university. The focus of our research was on student learning and faculty members teaching a combination of engineering content and process knowledge in particular those associated with a $21^{\text {st }}$ century engineering mindset. More specifically, we were seeking to determine the influence of working in the space on students' sense of belonging, professional identity development, and on their motivation for learning which included growth mindset and learning goal orientation.

\section{Review of Literature}

\section{$21^{\text {st }}$ Century Engineering Knowledge and Practices}

There is a growing body of research reporting the influence of makerspace work on student learning of engineering concepts and processes [4], [6], [11]-[13]. Makerspaces potentially provide a setting for fostering student development of critical engineering concepts and processes ranging from leadership characteristics [15] to understanding and application of the 
design cycle [4]. However, few studies have explicitly examined student learning through the lens of the knowledge and practice expectations of a $21^{\text {st }}$ century engineer [14]. Yet, $21^{\text {st }}$ century skills have been embraced by the Accreditation Board for Engineering and Technology (ABET) and are included in the standards for engineering programs [15]. The $21^{\text {st }}$ century skills include collaboration and teamwork, creativity, communication, emotional competency, cultural competency, ethics, leadership and management, critical thinking, and content knowledge. A fundamental shift in the ABET engineer paradigm with the adoption of the $21^{\text {st }}$ century framework reflects a focus on engineers as being at the service to society. The ABET standards suggest that there is justification for exploring the extent to which engineering student engagement in makerspaces is fostering and promoting their development of a $21^{\text {st }}$ century engineering mindset and their acquisition of $21^{\text {st }}$ century engineering knowledge.

\section{Sense of Belonging}

In makerspaces, students are likely to work closely with others or in teams on [16-21]. The social and cultural interactions that take place in the spaces likely influence the students learning [22] but also their sense of belonging. Yet, there is a need to empirically investigate the extent to which student interactions in the spaces influences their learning and how the culture within the spaces may lead to student feelings of inclusion or exclusion. The social interactions and the culture of the spaces may be key to documenting the influence on student learning, providing justification for documenting the levels of comfort in these spaces, feeling of belonging in the spaces, and the nature of student social interactions within the spaces.

As we shared before, a student's feeling of belonging in a learning environment is likely to impact their learning. Maslow's Hierarchy of Needs [23] states that human beings are motivated to feel a sense of belonging. It is possible that the learning that students gain from activities in makerspaces, is associated with their sense of belonging or a sense of being valued by others in the space. Thus, there is justification for determining what is taking place in the spaces to make people feel welcome in the spaces, and how the culture is being fostered to help students feel they belong in the spaces [23].

\section{Professional Identity Development}

The level to which individuals identify with a profession is influenced substantially by the level to which individuals hold schemas, engage in practices, and follow the norms of the profession [25]-[26]. If students perceive that they do not look, sound, act, and use tools like other engineering students, they may not identify with others doing engineering activities and, therefore, fail to develop and internalize an identity for the profession [27]. The opposite is true as well, if students can identify with the culture, the tool use, engineering tasks, and people associated with engineering activities they are most likely to develop and internalize an identity for the profession. We conjecture that engineering students' development of an identity in the engineering profession is influenced substantially is aligned with the culture or setting where they are learning about engineering. We speculate that in the setting of makerspaces students may form perceptions of their professional ability, a sense of belonging, and capacity to understand and carry out engineering activities. 
Given the high potential for an association between professional identity development and engagement in makerspaces, we maintain there is justification for examining the extent to which makerspaces might be designed and supported to foster students' professional identity development. The culture of most makerspaces may require the individuals in the space to assume a large level of responsibility for their learning and success in the spaces [27]. Assuming or owning the responsibility for success in a makerspace may require students to embrace and understand the norms, activities, and practices in the space - which we maintain are indicators of developing or growing a professional identity [25]-[26]. Understanding more about how makerspaces are, or are not, supporting students' professional identity development in a makerspace will allow us to determine whether these spaces are enhancing or hindering students learning and development as professional engineers.

\section{Motivation for Learning}

When considering motivation for learning, and work towards learning, we consider Dweck's concept of growth mindset [28], which highlights the importance of individuals' need to learn persevere through situations with unexpected outcomes they may encounter [28]. Alternatively, a learner who approaches situations with a fixed mindset would be unlikely to persevere when they experience failure and therefore would likely disengage from the additional efforts necessary to complete the task. We speculate that makerspace activities may foster a growth mindset as associated activities may encourage students to perceive trial and error, and failure, as instrumental to the learning and professional development process. Encouragement of repeated attempts and perception of failure in may, additionally, lead students to explore additional solutions with less fear.

We consider persistence as an indicator of motivation for learning as persistence is represented by sustained engagement and effort toward mastering understanding and completing assigned tasks particularly when encountering or perceiving challenges, barriers, failure, and/or adversity [29]. We considered the elements of motivation and persistence within the context of students learning engineering or engaging in engineering-based makerspace activities. Exploring persistence as it relates to the influence of makerspaces on undergraduate engineering students provides us with a framework for delving into how and why makerspace engagement may influence students' propensity to remain engaged in studying engineering despite facing academic challenges and barriers.

We also consider motivation through the framework of self-determination theory (SDT) [30]. We take into account SDT due to the intrinsic and extrinsic motives related to learning. Motivation for learning is critical in the makerspace environment where students are usually provided with an assignment to complete (an external motivator) that requires them to engage in the makerspace to complete (likely to involve some intrinsic motivation). We seek to document where motivation lies for students to engage in makerspace activities, on the extrinsic-intrinsic spectrum.

\section{Method}

\section{Research Questions}


Our overarching question for our research was: To what extent do engineering education programs that embed makerspaces foster student professional development, sense of inclusion, motivation to learn, and support professional identity development? To answer our primary research question, we developed the following guiding research questions:

1. To what extent do students working in the makerspaces convey a sense of belonging and increased motivation to learn and in what ways do faculty members, staff, and the director convey an expectation for students feeling a sense of belonging and increased motivation to learn when working within a makerspace?

2. To what extent do students working in the makerspaces convey perceptions reflective of professional identity development, and learning more about engineering, and in what ways do faculty members, staff, and the director convey an expectation for students to experience increases in their professional identity development and knowledge of engineering when working within a makerspace?

3. What do faculty members and students perceive to be necessary for students to be successful within a makerspace?

\section{Participants and Setting}

The participants in our study were the students, staff, and faculty members interacting with or working within an engineering program embedded makerspace during two days of data collection. The setting was a large, public, and high research activity university in the southern region of the United States with large undergraduate and graduate engineering education programs. We limited our demographic data collection across three roles at the university (student, faculty member, or staff), which we report out alongside and gender. To maintain the participants' anonymity, we did not gather additional detailed personal information. We interviewed four faculty members, five staff members, the director, and more than 20 students.

To preserve the anonymity of the participants and institution, we also describe the space in general terms. The makerspace of our focus was large and centrally located within a cluster of buildings used for STEM research, teaching, and faculty offices. The space was free to use (including many materials) and open to all students taking engineering classes. The space was accessible daily and open at selected times on the weekend. There are other spaces on the campus that non-engineering students could use for making and working on projects. The space had staff and a director and included an array of machines and tools that could be used for prototyping. Students were encouraged to work on personal projects and were provided some of the needed materials free of charge if the projects were small. If the projects were large, the student was expected to purchase the supplies. Students had access to almost all of the equipment after being taught how to use the equipment by the space staff and then demonstrating competency in the use of the tools. 
Student use of the space was integrated to some level in approximately 30 courses (i.e. students were given assignments that required them to use a makerspace to complete), from introductory courses that open to non-engineering students to capstone design courses for senior engineering majors. The number of courses for which the space was utilized by students was expected to increase in the next academic year.

\section{Data Collection}

We have designed our project using both instrumental and collective case study frameworks [31]. We are currently in our instrumental case study phase, detailing the particulars of each university program. Following the completion of our instrumental work we will engage in a collective case study framework to determine similarities and differences across programs to form a comprehensive perspective of makerspaces embedded within engineering education programs.

The cases for our research are university undergraduate engineering education programs that have College of Engineering integrated makerspaces. To collect data from these spaces we are using a combination of surveys, observations, and interviews. The focus of our report is on the interview data that we gathered from a single case.

We gathered the data through interviews of students using the space, faculty members integrating the student use of the space into their curriculum, and staff and director managing the space. We arranged some faculty member, staff and director interviews prior to visiting the university. We were able to make additional interview appointments with faculty members once we were on the campus. The interviews lasted about 20 to 30 minutes.

To interview the students, we approached students working in the makerspace and asked them if they had time to share some of their thoughts about working the space. Some of the student interviews were relatively brief, about 5 to 10 minutes, others lasted longer, 20-30 minutes. The interviews varied based on the students' interest in talking to us, the time they had available to talk to us, and their level of comfort in talking with us.

We recorded the interviews and transcribed them verbatim for analysis.

\section{Interview Protocol}

We developed two semi-structured interview protocols, one for students working in makerspaces, and another for faculty members, staff, or space directors working within the spaces. In our development of the student interview protocols we created a series of discussion prompts to focus student conversation on their perceptions, interactions, and work within the space. We aligned the prompts to our major constructs of motivation, professional identity, belonging, and learning of engineering. We contextualized the prompts to make them relative to the interactions students might experience in makerspaces. For example, one prompt asks, "What's the value of being in a makerspace?" which could allow for exploration of constructs of persistence, professional identity development, competency, motivation and belonging via students' references, for example, to learning more about the processes of engineering (such as 
collaborating on a project), increased motivation to work on their projects (even when the projects were difficult to complete), or a sense of being part of a community in the space. Our student interview protocol included ten prompts. We validated the interview protocol by sharing with a group of six experts in makerspace development and use.

We took an approach similar to the development of the student protocol to create the faculty member, director, and staff interview protocol. Again, we developed a series of prompts aligned with our major constructs. However, we contextualized the questions to focus the conversation on ideas such as expectations for students using the space, integration of the space into the curriculum, and assessing the success for student use in the space. For example, one prompt asks, "Are there other things you are hoping students gain from their participation in makerspaces?" Similar to the student protocol prompt we shared, we anticipated that the faculty member, staff, and director prompt would solicit responses that would include references to all of our major study constructs. The protocol includes sixteen prompts. Again, we validated the interview protocol by sharing with a group of six experts in makerspace development and use.

\section{Data Analysis - Coding}

To analyze our data, we used a combination of a-priori and emergent codes. We developed our a priori codes for the major constructs of our study based on relevant literature and contextualization for our research. For example, a priori codes concerning sense of belonging are partially based on the work of Maslow [23] and the essential need to belong which includes friendship, trust, acceptances and being part of a group. Contextualizing belongingness for student engagement in makerspaces codes results in codes for feeling comfortable in the space and feelings of inclusion in the space (see Table 1). The codes are indicators of the attributes associated with each of the constructs. We achieved intercoder agreement by independently coding one transcribed interview and then compared our outcomes. Our results overlapped at nearly $90 \%$, which indicates acceptable coding reliability. Once we established the agreement we divided the transcripts for coding. We also remained opened to the possibility that our participants may share unanticipated perceptions or experiences and, therefore, we remained open to emergent coding. When we found other area themes emerging that we did not anticipate we communicated the finding and worked together to develop an appropriate set of codes. See Table 1 for the construct-aligned codes we used to analyze our data.

\section{Results}

Table 1: Study Constructs, Associated Codes, and Examples of Representative Responses

\begin{tabular}{|l|l|l|}
\hline Construct & Codes & Example Representative Responses \\
\hline
\end{tabular}




\begin{tabular}{|c|c|c|}
\hline $\begin{array}{l}\text { Sense of } \\
\text { Belonging }\end{array}$ & $\begin{array}{l}\text { Holding a role within the space, } \\
\text { sense of purpose, emotions, } \\
\text { availability of knowledge, } \\
\text { accessible and visible, } \\
\text { intimidation, student perceptions, } \\
\text { inclusion, breaking barriers, } \\
\text { students feeling comfortable } \\
\text { within the space, tailoring } \\
\text { environment to students }\end{array}$ & $\begin{array}{l}\text { Student: "belong? just like have a sense of like } \\
\text { responsibility here?" } \\
\text { Student: "I think it's more inviting just because it's so } \\
\text { central in this building." } \\
\text { Director: "We didn't want to have any kind of barriers } \\
\text { whatsoever. So we picked those color tones to make it } \\
\text { really inviting for everybody." }\end{array}$ \\
\hline Motivation & $\begin{array}{l}\text { Desire to work/learn, use of } \\
\text { equipment for coursework, use of } \\
\text { equipment for personal projects, } \\
\text { ease in learning, application of } \\
\text { skills, enthusiasm, engagement, } \\
\text { self-efficacy, struggle, creative } \\
\text { expression }\end{array}$ & $\begin{array}{l}\text { Student: "It's like we don't want to spend more time } \\
\text { here than we have to. I mean not in a bad way like I } \\
\text { love this space." } \\
\text { Student: "So I'd really like to come in and make } \\
\text { something I've just been busy you know." } \\
\text { Director: "It's people that I see here on a daily basis } \\
\text { coming in utilizing the equipment, having that spark, } \\
\text { that desire to be here." }\end{array}$ \\
\hline $\begin{array}{l}\text { Affordances and } \\
\text { Challenges }\end{array}$ & $\begin{array}{l}\text { Student independence, } \\
\text { individualized learning, process } \\
\text { of learning, safety, autonomy, } \\
\text { forced adaptations, constrained } \\
\text { time for faculty and students, } \\
\text { challenges, sustainability, } \\
\text { resource availability, use of } \\
\text { resources, space limitations, } \\
\text { expenses associated with } \\
\text { makerspace }\end{array}$ & $\begin{array}{l}\text { Student: "... and then timing management is, well like } \\
\text { we said another big lesson." } \\
\text { Faculty: "Well I think probably the biggest skill, I don't } \\
\text { know if it's a skill, life skill is not procrastinating." } \\
\text { Staff: "When using a CNC machine for the first time } \\
\text { you're probably going hurt somebody if you mess } \\
\text { something up" } \\
\text { Faculty Member: "There's only room for about } 6 \text { or } 7 \\
\text { projects in the semester. So which ever one you choose } \\
\text { to focus on, that's going to eliminate another one." }\end{array}$ \\
\hline $\begin{array}{l}\text { Curriculum } \\
\text { Integration of } \\
\text { Makerspace }\end{array}$ & $\begin{array}{l}\text { Coursework, skill building, use of } \\
\text { the space, projects, training, } \\
\text { group activities, application of } \\
\text { knowledge learned, faculty } \\
\text { involvement, learning } \\
\text { opportunities }\end{array}$ & $\begin{array}{l}\text { Faculty Member: "I think as people hear about it } \\
\text { they'll start to think" oh maybe instead of a homework } \\
\text { assignment they can make something." } \\
\text { Student: "We only have so many hours in class where } \\
\text { you're just learning theory right? In here you're actually } \\
\text { applying stuff." } \\
\text { Student: “...because these 3D printers are actually } \\
\text { shifting the way that class is designed. We now take } \\
\text { things a step further and produce an actual, physical } \\
\text { deliverable." }\end{array}$ \\
\hline $\begin{array}{l}\text { Learning } \\
\text { Engineering and } \\
\text { Professional } \\
\text { Identity } \\
\text { Development }\end{array}$ & $\begin{array}{l}\text { Working with a client, } \\
\text { resume/skill building, } \\
\text { engineering skills, trial and } \\
\text { failure, practical applications, } \\
\text { real world use of skills, career } \\
\text { goals of students, collaboration, } \\
\text { prototyping, decision making, } \\
\text { gaining experience }\end{array}$ & $\begin{array}{l}\text { Student: "Whereas now I have that experience. Now I } \\
\text { can add more things to my resume." } \\
\text { Faculty Member: "I think we really just strengthen } \\
\text { those hardcore engineering criteria." } \\
\text { Staff: "You learn through failure. Mess up! Mess up } \\
\text { because you're going to learn the most from messing } \\
\text { up." }\end{array}$ \\
\hline
\end{tabular}

\section{Results}

\section{Belonging and Motivation}

Our first guiding research question asked, In what ways do Do students working in the makerspaces convey a sense of belonging and increased motivation to learn and do in what ways 
do faculty members, staff, and the director convey an expectation for students feeling a sense of belonging and increased motivation to learn when working within a makerspace? To answer this research question we coded our transcripts for perceptions of belonging and motivation to learn.

We found multiple instances in which students indicated that they felt welcome in the space such as what this student shared, "I definitely believe that we belong here as engineers because this was given to us for that purpose." The director of the space works to assure students feel included as is apparent by this response, "I want to break down that those little barriers, whatever they are and just make them feel comfortable and welcome and tell them that hey, you don't have to know what's going on and there's training here for you and you don't have to be intimidated." Thus, students indicated coming into the space knowing how to use the equipment, and the director worked to create an environment of inclusion.

In a conversation with three self-identified female students who were in the space for their second time, they shared that they were reluctant to visit the space their first time because they did not know what to expect. They shared that they had a successful experience and felt welcomed and valued and therefore, had no hesitation returning to the makerspace to continue working on their project. The conversation reflects a sense of comfort and inclusion in the space for these students. We encountered a similar response from two other female students who were working on homework in the space and enjoyed being in the space because it was stimulating and they felt comfortable working in the space.

To determine if students were motivated by the space, we coded the interview transcripts for indicators of engagement, interest, and initiative. We found that many students enjoyed exploring in the space beyond working on their assignments, but when working on course assignments, the students were really engaged. We had multiple conversations with groups of students working together on courses assignments. (Note: several of these conversations were unanticipated and therefore, were not recorded.) It was in these conversations that we found the students indicating that they were excited about working on the assignments, as when students indicated that they were spending more time on the projects than they typically did on more traditional assignments due to developing solutions they could create by using the tools in the makerspace. In our conversation with a faculty member who held office hours in the space, he shared, "It's people that I see here on a daily basis coming in utilizing the equipment, having that spark, that desire to be here." This supports our earlier conclusion that students using the space are motivated to be there and are engaged when they are in the space. Many of the responses of the students reflect a similar level of motivation to be in the space and engage in learning activities. For example, one student shared, "It's free to students. You only have this opportunity while you're here. I really like to come in and make something." Thus, the students are motivated to visit the space and use the space for working on projects.

\section{Professional Identity Development and Learning Engineering}

Our second guiding research question asked: In what ways do students working in the makerspaces convey perceptions reflective of professional identity development, and learning more about engineering, and in what ways do faculty members, staff, and the director convey an 
expectation for students to experience increases in their professional identity development and knowledge of engineering when working within a makerspace?

To answer this research question, we coded our transcripts for perceptions of belonging and motivation to learn. Our analysis revealed that faculty members perceived that students are gaining valuable skills in the space as is indicated by this response, "Students learn the skills which are beneficial to a student's professional development: adding skills to resumes, presentations of projects, and creating a product for a client." The creation of client products and presentations are fundamental engineering processes and require professional skills and knowledge which seems to be reinforced by work within the space. Another faculty member shared a similar perspective in the response, "I think we really just strengthen those hardcore engineering criteria."

The students also indicated that they were learning more about engineering in the space as indicated by this response, "We've already had to make some solutions-modifications. I think that applies to life as well as engineering, because you know, it's never going to go 100 percent to plan." Similarly, a student responded with, "It's nice to feel that push from professors to incorporate the use of the space in their classes, to let us know that it's okay to experiment and it is okay to do it once and okay if it doesn't come out how you wanted it to."

In the space the students were almost always working in teams, particularly on assigned projects. The communication, collaboration, and interactions are aligned with the norms and practices of professional engineers. Thus, the space reinforces student development of a professional identity. The autonomy and support for the students in the space further provides them with the opportunity to internalize the opportunity to gain the skills and knowledge of a professional, leading to opportunities for professional identity development. Also, the nature of the assignments in the space reinforce the potential for professional identity development, as this faculty member shared, "It's good for them to be ambitious, but if they're ambitious and fall short, which they probably will, there's value in that." Given that dealing with failure and persisting via it are fundamental to a professional engineering mindset, makerspaces may provide opportunities to further develop an identity as a professional.

\section{Other Space Considerations For Student Success}

Our third guiding research question asked: What do faculty members and students perceive to be necessary for students to be successful within a makerspace? To answer this question we analyzed our data focusing on the barriers and affordances associated with working in the space. We exposed two major themes: time and safety. Time was conveyed as a barrier by both faculty members and students, as both expressed the need to exercise additional time management skills within the space. As one student shared, "And then time management is, well, like we said another big lesson." Similarly, a faculty member expressed that students often share that they learn time management skills in the space. Yet, some faculty members realize that they need more time to effectively use the space in their courses. As one faculty member shared, "I find it embarrassing that I do not know how to do this stuff. I wanted to go do the 3D printing assignment but there's just like..." (Interviewer) "Time?" (Faculty)" I have to do proposals." Thus, while faculty members want to use the space they have competing responsibilities that 
may take precedence, which limits the ability to develop meaningful and appropriate assignments. As this faculty member shared, "So they could end up easily spending 20 or 30 hours at it and it's just not worth it." indicating that makerspace assignments could be structured in ways that take significant time with learning outcomes that are less than expected given the time invested.

Another major consideration that was shared multiple times by staff and the director were issues of safety. As the director shared, "You've got to look at the safety aspects. You invite environmental health and safety in to determine the requirements here at the university to actually introduce new equipment." Thus, while efforts are in place to create a space with a range of capacity to foster innovation, there are certain challenges with safety that may limit opportunities because of cost or physical feasibility.

\section{Discussion and Implications}

The primary goal of our research was to determine what faculty and students perceive are afforded students through their experiences in engineering education program embedded makerspaces. In particular, we were interested in determining what the students were learning about engineering, to what extent the experiences helped the students develop their identity as professionals, and how working in the space may motivate students to learn and feel like they are included in the engineering community.

Given the limitations of this study, we speculate that the activities and expectations of working within makerspaces may foster student motivation to learn. One of the primary functions of the engineering education program makerspace is to support rapid prototyping. Part of the prototyping process is working on open-end problems with multiple potential solutions. Because there is no one correct answer the students have much more latitude to explore and develop different solutions. We posit it is the open-ended nature of the problems that lead students to be motivated to work in the spaces. Further, the ability to develop rapid prototypes in the space makes the cost of change lower and encourages students to continue to explore new possibilities.

We found evidence of students expressing a sense of belonging in the space. We attribute their sense of belonging to the community that has been established within the space through the removal of barriers and creating a non-intimidating environment. We found a concerted effort to make the space inviting and pleasant to work within. The creation and support for students as a community of learners in the space, and providing the resources and training to use the tools and equipment led the students to have positive experiences in the space. Leadership may be important to creating an inclusive environment, as per director claims.

We found that students gained deeper understanding of engineering via working within the space. We posit that the processes of the activities that the students work on in the space and the availability of the tools to experiment with different solutions leads students to understand the importance of failure, collaboration, critical thinking, optimization, and constraints. The students also indicated that they were able to apply their knowledge in the space toward the development of a product, a process that was not taking place in their more traditional coursework. The faculty members' recognition of the learning benefits from working in the space may lead to 
additional curriculum integration and more opportunities for student learning through the application of knowledge which may help them further develop as engineers.

We found that the spaces supported students' development of professional identities. We speculate that the autonomy that students have in the space, the nature of their assignments in the space, and the culture within the space all foster student development of perceptions of being part of a professional community. Further, we conjecture that the support the students have in the space to explore requires the students to take responsibility for the time in the space (i.e. time management) which is a very important professional skill. Because the spaces are more student centered and less structured than more traditional learning environment, the spaces are ideal for supporting activities that are aligned with professional engineering, which further fosters student internalization of themselves as professionals. By integrating makerspace activities into the curriculum, faculty members can help catalyze student development as professional, positively impacting their development of an identity that includes being a professional.

Our analysis revealed that time and safety were aspects of makerspace use that we did not anticipate to be so prevalent. The issue of time is a noteworthy consideration when structuring lessons for students. Because of the open-ended nature of many of the projects in the space, students could spend considerable amounts of time in the space working on the projects and exploring multiple potential solutions. Thus, faculty members may need to prepare their students to consider their time (and associated management of their time) within the space so that work in the space is not at the expense of other commitments or responsibilities. Thus, when assigning makerspace assignments, faculty members may want to have the students monitor their time on the projects and collect the data from the students and use the information to refine the assignments to optimize learning.

The attention to safety in the spaces is essential, particularly with large milling machines, cutters, and other power tools. The potential for harm in the spaces due to lack of knowledge or careless use was being addressed through training and monitoring. Again, the leadership in the space took a progressive approach to not access but rather prepare people to use the equipment properly through educating them. We maintain that through attention to safety, students can be more engaged and productive in the spaces, and can also gain a deeper understanding of safety in the workplace, which influences their engineering knowledge and professional identity.

\section{Limitations}

Our first limitation is that our data is from a single case of a university engineering education program embedded makerspace. Therefore, the perceptions, experiences, and expectations for makerspaces in engineering education may be very different at other institutions. However, through our case study analysis we were able to gain beginning understanding of the experiences of students in the spaces, faculty member uses and expectations for the space, and the influence of the use of the space on an array of constructs. We are gathering data from other cases and continue to explore how the spaces are similar or different for student learning and development.

The second limitation of our research was the limited number of students and faculty members we were able to interview. We did talk with over 20 students and 4 faculty members, but given 
there are thousands of students and hundreds of faculty members, the perceptions and expectations and experiences of our participants may not have been representative of the larger college community. Gathering data from additional participants will allow us to develop a more accurate representation of the greater university engineering education community.

A third limitation of our research was our focus on the students who used the space, and did not seek data from those students who avoided being in the space. Gathering data from those who chose to be in space may have resulted in telling only half the story, reflecting the perspectives of only those who felt comfortable and included in the space. We would have liked to gather data from those students who perceived that they were not welcome in the space or avoided the space for other reasons, but we had no way of readily locating these students. As we move forward with our research gathering data from students who were avoiding using the space would be a very interesting direction for our research.

\section{Conclusion}

We are seeking to better understand what students are learning and experiencing in makerspaces embedded into university engineering education programs. Thus, we are conducting a case study research project of makerspaces embedded in undergraduate engineering education programs. We are considering an array of variables that are associated with student knowledge, retention, engagement, and professional development. The evidence that we gathered at the case we detailed in this report indicates positive support for student learning and development as engineers. The structure, management, use, culture, and support within the space made the space inviting for students. The students in the space were gaining from their experiences. Our results indicate that if makerspaces are created and supported effectively, the students working in the spaces are more likely to experience positive gains in their journey preparing to be engineers.

This material is based upon work supported by the National Science Foundation under Grant No. 1664272. Any opinions, findings, and conclusions or recommendations expressed in this material are those of the author(s) and do not necessarily reflect the views of the National Science Foundation. 


\section{References}

[1] N. Lou and K. Peek, "By the numbers: The rise of the makerspace," Popular Science (2016). [Online]. Available: http://www. popsci. com/rise-makerspaceby-numbers. [Accessed Feb. 4, 2019].

[2] V. Ortega, "Increasing STEM exposure in K-5 schools through MakerSpace Use: A Multisite early success case study," Ph.D. dissertation, College of Edu., Univ. Calif. Los Angeles, 2017.

[3] K. Sheridan, E. R. Halverson, B. Litts, L. Brahms, L. Jacobs-Preibe, and T. Owens, "Learning in the making; A comparative case study of three makerspaces," Harvard Educational Review, vol. 84, no. 4, pp. 505-531, 2014.

[4] V. Wilczynski, “Academic maker spaces and engineering design,” presented at $122^{\text {nd }}$ Ann. conf. and expo. American Society Engineering Education, Seattle WA, USA, June 14-17, 2015, 2004, pp. 26.138.2-26.138.19.

[5] A. Wong and H. Partridge, "Making as learning: Makerspaces in universities," Australian Academic and Research Libraries, vol. 47, no. 3, pp. 143-159, 2016.

[6] M. Galaledin, F. Bouchard, H. Anis, and C. Lague, "The impact of makerspaces on engineering education," Proc. Canadian Engineering Educations Association (CEEA) Conf., June 19-22, 2016, Halifax, NS, Canada, 2016.

[7] E. Hilton, M. Tomko, A. Murphy, R. Nagal, J. Linsey, "Impacts on design self-efficacy for students choosing to participate in a university makerspace, in DS 89: Proc. 5th Int. Conf. on Design Creativity, University of Bath, Bath, UK, 2018, pp. 369-378.

[8] R. J. Morocz, B. Levy, C. Forest, R. L. Nagel, W. C. Newstetter, K. G. Talley, and J. S. Linsey, "Relating student participation in university maker spaces to their engineering design self-efficacy, in American Society for Engineering Education Ann. Conf. Proc., June 26-29, 2016, New Orleans, LA, USA, 2016.

[9] M. M. Hynes and W. J. Hynes, "If you build it, will they come? Student preferences for Makerspace environments in higher education," International Journal of Technology and Design Education, vol. 28, no. 3, pp. 867-883, 2018.

[10] J. L. Saorin, D. Melian-Diaz, A. Bonnet, C. C. Carrera, C. Meier, and J. De La TorreCantero, "Makerspace teaching-learning environment to enhance creative competence in engineering students," Thinking Skills and Creativity, vol. 23, pp. 188-298, 2017.

[11] M. Z. Lagoudas, J. E. Froyd, J. L. Wilson, P. S. Hamilton, and R. Boehm, “Assessing impact of makerspace on student learning," 123rd ASEE Ann. Conf. and Expo. New Orleans, LA, 2016. 
[12] T. V. Cook, J. A. Lyle, and R. J. Kerestes, "Work in progress: Reinforcement of engineering educations with hands-on leanring of technical skills," in 2018 ASEE Ann. Conf. and Expo., June 2018.

[13] S. Park, H. Kaplan, R. Schlaf, and E. Tridas, "Makecourse-Art: Design and Practice of a Flipped Engineering Makerspace," International Journal of Designs for Learning, vol. 9 ,no. 1, pp. 98-113, 2018.

[14] J.L. Oplinger, M. Lande, and S.S. Jordan, "Leadership characteristics within the making community,"ASEE Ann. Conf. and Expo., Seattle, WA, 2015.

[15] B. Hawthorne, Z. Sha, J. H. Pancal, F. Mistree, "Developing competencies for the 21st century engineer," in ASME 2012 Int. Design Engineering Technical Conf. and Computers and Informaiton in Engineering Conf., American Society of Mechanical Engineers, August 2012, pp. 151-160.

[16] R. J. Morocz, B. D. Levy, C. R, Forest, R. L. Nagel, W. C. Newstetter, K.G. Talley, and J. S. Linsey, "University Maker Spaces Discover, Optimization and Measurement of Impacts," ASEE Ann. Conf. and Expo., Seattle, WA, 2015.

[17] C. Forest, R.A. Moore, A.S. Jariwala, B.B. Fasse, J. Linsey, W. Newstetter, P. Ngo, and C. Quintero, "The Invention Studio: A University Maker Space and Culture," Advances in Engineering Education, vol. 4, no. 2, pp. 2, 2014.

[18] T.W. Barrett, C.M. Pizzico, B. Levy, and R.L. Nagel, "A Review of University Maker Spaces," ASEE Ann. Conf. and Expo., Seattle, WA, June 2015.

[19] M. Tate and S. Norris, "A Maker Space of their own," ASEE Prism, vol. 24, no. 2, Oct. 2014.

[20] P. Rees, C. Olson, C.M. Schweik, and S.D. Brewer, "Work in Progress: Exploring the Role of Makerspaces and Flipped Learning in Town- Gown Effort to Engage K12 Students in STEAM," ASEE Ann. Conf. and Expo., Seattle, WA, 2015.

[21] S. C. Georgie, "If You Build It Will They Come? Building a FabLab in the University of Texas@ Arlington Libraries and Building Faculty Partnerships for Its Use," ASEE Ann. Conf. and Expo., Seattle, WA, 2015.

[22] L.S. Vygotsky, "Mind in society: The development of higher psychological processes," Harvard University Press, Oct. 151980.

[23] A. H. Maslow, “A Theory of Human Motivation.” Psychological Review, vol. 50 ,no. 4, pp. 370-396, 1943. 
[24] C. E. Foor, S. E. Walden, and D. A. Trytten, "'I wish that I belonged more in this whole engineering group':Achieving individual diversity," Journal of Engineering Education, vol. 96 no. 2, pp. 103-115, 2007.

[25] L.S. Nadelson, S.P. McGuire, K.A. Davis, A. Farid, K.K. Hardy, Y.C. Hsu, and S. Wang, "Am I a STEM professional? Documenting STEM student professional identity development," Studies in Higher Education, vol. 42, no. 4, pp. 701-720, 2017.

[26] I. Villanueva and L. Nadelson, "Are We Preparing Our Students to Become Engineers of the Future or the Past?" International Journal of Engineering Education, vol. 33, no. 2, pp. 639-652, 2017.

[27] J. Mekolichick and J. Wirgau, "Leveraging the Maker Movement for Undergraduate Research: Developing a Making and Innovation Culture" Council on Undergraduate Research Quarterly, vol. 37 no. 4, 2017.

[28] C. Dweck, "What having a "growth mindset" actually means," Harvard Business Review, vol. 13, [Online]. Available: http://thebusinessleadership.academy/wpcontent/uploads/2017/03/What-Having-a-Growth-Mindset-Means.pdf. [Accessed Feb. 4, 2019].

[29] D. Allen "Desire to finish college: An empirical link between motivation and persistence," Research in Higher Education, vol 40, no 4, pp. 461-485, 1999.

[30] R. M. Ryan and E. L. Deci, "Self-determination theory and the facilitation of intrinsic motivation, social development, and well-being," American psychologist, 55(1), 68, 2000.

[31] R. E. Stake. The Art of Case Study Research. Thousand Oaks, CA: Sage; 1995. 